für politische Bildung und andere Bildungseinrichtungen). Von 1994 bis 2003 war sie Vorstandsmitglied der Hamburgischen Anstalt für neue Medien, vier Jahre Vorstandsvorsitzende, seit 1995 ist sie Fernsehproduzentin („Luzifilm Hamburg“), Mitglied einer Vielzahl beruflicher Verbände und Jurys. Sie erhielt Auszeichnungen wie den Jakob-Kaiser-Preis, den Eduard-Rhein-Kulturpreis, den Pressepreis des Deutschen Anwaltvereins und die Hedwig-Dohm-Medaille des Journalistinnenbundes. Ihr neustes Projekt ist ein Informations- und Lehrfilm zum Thema „Hilfen für Kinder bei Trennung und Scheidung " für die Deutsche Liga für das Kind, Berlin. Im djb war sie zwei Jahre Mitglied des Bundesvorstandes.

Rechtsanwältin Dr. Gisela Wild wurde am 18. September 1932 in Bad Warmbrunn (Riesengebirge) geboren. Sie begann 1952 ihr Jurastudium in Freiburg und folgte damit dem Wunsch ihres Vaters - eines Finanzbeamten -, „Kronjuristin“ zu werden. Ihr Referendariat absolvierte sie in Baden-Württemberg, Köln und Hamburg. 1960 promovierte sie über das Thema „Leopold August Warnkönig, 1794 bis 1866: ein Rechtslehrer zwischen Naturrecht und historischer Schule und ein Vermittler deutschen Geistes in Westeuropa " und wurde 1961 als 16. Rechtsanwältin in Hamburg zugelassen (Kanzlei Prof. Bussmann, Dr. Droste, gewerblicher Rechtsschutz, Urheberrecht, Presserecht). 1970 trat sie als erste Partnerin in die Kanzlei v. Berenberg-Gossler, Frhr. v. Gleichenstein ein, die 1990 durch Fusion mit anderen Kanzleien zu einer der ersten überörtlichen Sozietäten in Deutschland wurde, 2002 zur internationalen Kanzlei Taylor Wessing. 1978 wurde sie im sogenannten „Emma“-Prozess bekannt, erkämpfte dann 1983 mit ihrer Kollegin Maja Stadler-Euler vor dem Bundesverfassungsgericht das Recht auf informationelle Selbstbestimmung als Grundrecht (sog. Volkszählungsurteil). 1996 erhielt sie das Bundesverdienstkreuz, 2005 wurde sie von der Bürgerschaft als Hamburgische Verfassungsrichterin gewählt, 2010 erhielt sie den erstmals verliehenen Maria-Otto-Preis des Deutschen Anwaltvereins. Im djb war sie von 1977 bis 1979 zweite Vorsitzende, bis 1983 Vorstandsmitglied.

Heike Mundzeck und Rechtsanwältin Dr. Gisela Wild wird von ganzem Herzen für ihre langjährige Unterstützung gedankt: Wir gratulieren erneut!

\title{
Die Regionalgruppe Bonn feiert die 35-jährige djb-Mitgliedschaft von djb-Ehrenpräsidentin Antje Sedemund-Treiber
}

Antje Sedemund-Treiber, geb. 1936 in Kiel, begann ihren beruflichen Weg als Richterin am Verwaltungsgericht und wechselte 1968 für fast 25 Jahre in das Bundesministerium der Justiz. Ab 1988 war sie die erste Leiterin der Unterabteilung $B$ in der Abteilung für Justizverwaltung, die an Mitarbeitern stärkste Unterabteilung im Bundesjustizministerium. Von 1992 bis zu ihrer Pensionierung im Jahr 2001 war Antje Sedemund-Treiber Präsidentin des Bundespatentgerichts in München.

1977 trat sie dem djb bei und war für die ersten zehn Jahre ihrer djb-Mitgliedschaft Vorstandsmitglied der Regionalgruppe Bonn. Von 1985 bis 1993 war sie Bundesvorstandsmitglied, davon vier Jahre (1989-1993) als Erste Vorsitzende. Von 1990 bis 1993 leitete sie sowohl den

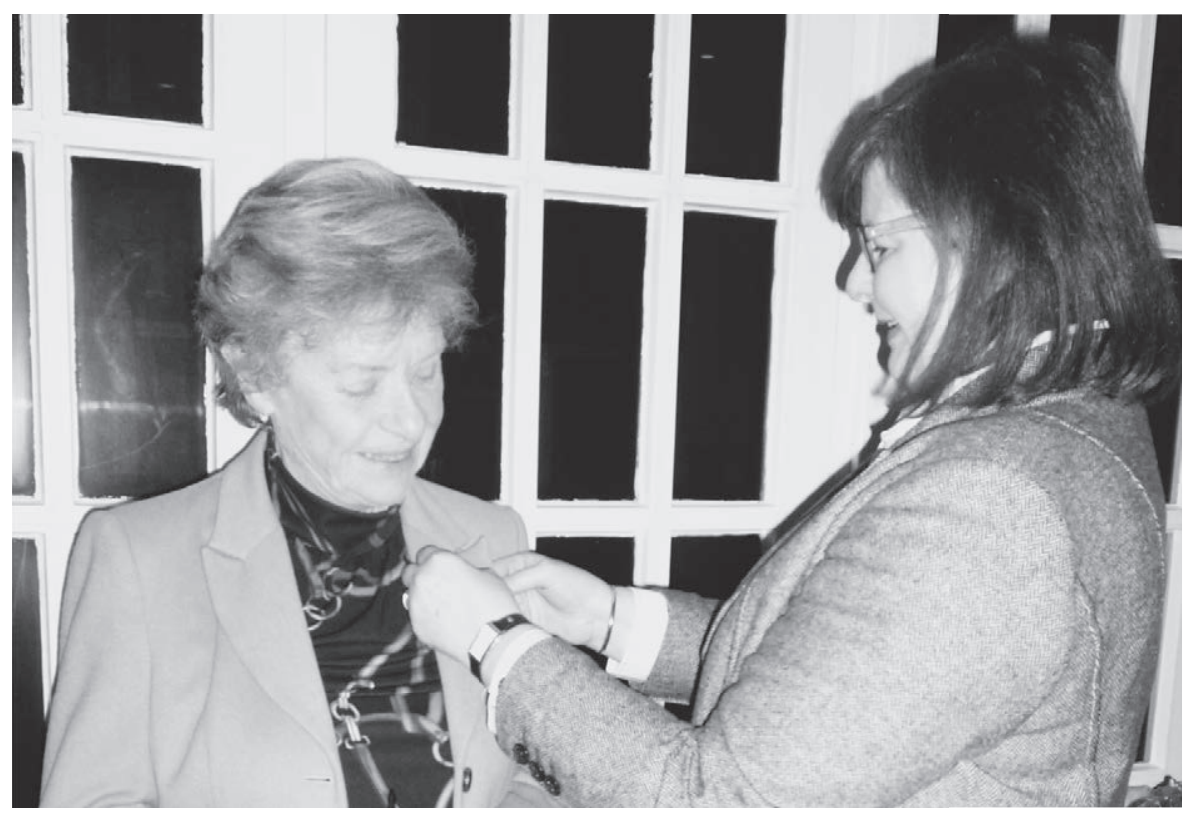

$\Delta$ Antje Sedemund Treiber (links), Ehrenpräsidentin des djb, erhält am 8. März 2012 von Andrea Rupp, Vorsitzende der Regionalgruppe Bonn im djb, eine Nadel für 35-jährige djb-Mitgliedschaft.
Arbeitsstab Beamtenversorgung als auch den Arbeitsstab Deutsch-deutsche Rechtsbeziehungen. 1992 und 1993 saß sie außerdem der djb-Verfassungskommission vor. Nicht zuletzt ihrem herausragenden Engagement verdankt es der djb, dass in den Diskussionen nach der Wiedervereinigung Artikel 3 Absatz 2 GG um die Aufforderung an den Staat ergänzt wurde, „die tatsächliche Durchsetzung der Gleichberechtigung von Frauen und Männern“ zu fördern und ,auf die Beseitigung bestehender Nachteile" hinzuwirken. 2008 wurde sie im Rahmen einer Feier zum 60. djb-Geburtstag im Deutschen Bundestag zur Ehrenpräsidentin des Verbands ernannt. 